\title{
STUDIES OF SAHARAN DUST INTRUSIONS OVER BUCHAREST USING CEILOMETER'S MEASUREMENTS AND SATELLITE DATA
}

\author{
Denisa Urlea $^{1,2^{*}}$, Andreea Boscornea ${ }^{3}$, Sorin Nicolae Vâjâiac ${ }^{3}$, Florica Ţoancă ${ }^{4}$, Nicu Barbu ${ }^{2}$, \\ Sabina Ştefan ${ }^{1}$, Ionuț Bunescu ${ }^{3,5}$ \\ ${ }^{1}$ University of Bucharest, Faculty of Physics, Măgurele - Ilfov, Romania \\ "denisaurlea@gmail.com \\ ${ }^{2}$ Romanian Air Traffic Services, Bucharest, Romania \\ ${ }^{3}$ National Institute for Aerospace Research "ElieCarafoli", Bucharest, Romania \\ ${ }^{4}$ National Institute of Research \& Development for Optoelectronics, Măgurele - Ilfov, Romania \\ ${ }^{5}$ POLITEHNICA University of Bucharest, Faculty of Aerospace Engineering, Bucharest, Romania
}

\begin{abstract}
Three case studies of Saharan dust intrusions over southern Romania were performed. For these studies the database from the ceilometers located at Magurele and Strejnic was used. In addition, the meteorological conditions were analyzed using the WLK Catalogue based on the Objektive Wetterlagenklassifikation classification of the weather types [1]. This catalogue uses information from three basic tropospheric levels: 925, 700 and $500 \mathrm{hPa}$, and information on the precipitable water content over the entire atmosphere column. Geopotential fields at $925 \mathrm{hPa}$ and $500 \mathrm{hPa}$ are used for establishing the cyclonicity or anticyclonicity, while the $\mathrm{U}$ and $\mathrm{V}$ components of wind at $700 \mathrm{hPa}$ for establishing the dominant direction of the wind flow. For better understanding of the atmospheric parameters we performed HYSPLIT dispersion and trajectories analysis in conjunction with DREAM model output data.
\end{abstract}

\section{INTRODUCTION}

The desert dust aerosol is an important factor of impact for the European regional climate. The most intense and persistent activity occurs in the southern part of the Tell Atlas Mountain, Tunisia and North-East of Algeria having a maximum on April-May often extending to August-September [2] and follows a Mediterranean path to Central and Eastern Europe [3]. Romania can be considered as being relatively close to the source region taking into account that over Belgrade were found 3.5 up to $9.8 \mu \mathrm{m}$ diameter Saharan dust particles over two years of studies [4] and a major event took place over Germany in April, 2014 [5].

This study is exploring the capabilities of CL31 VÄÏSÄLA ceilometer to monitor, evaluate and describe the aerosols, focusing on Saharan dust intrusions over southern Romania, particularly at Magurele and Strejnic, two sites nearby Bucharest. The geographical and meteorological conditions are presented in Section 2.1. Three months were investigated (July, August and September 2016) of coincident data at the two locations and the matching dates with possible dust intrusions forecasted by the DREAM model. All data and images were derived from the BSC-DREAM8b and the NMMB/BSC-Dust models, operated by the Barcelona Supercomputing Center (http://www.bsc.es/ESS/). Three study cases were selected for the analysis. Data and methods used are presented in Section 2.2. In Section 3 we discuss the vertical profiles from simultaneous ceilometers aerosol backscatter coefficients, satellite imagery and synoptic meteorological data. The concluding remarks end our paper.

\section{METHODOLOGY}

\subsection{Instruments and Measuring Sites}

In this paper we studied three Saharan dust intrusion cases over Romania using two ceilometers. These instruments are traditionally been used only to report cloud base height and vertical visibility [6]. Ceilometers are also useful in studying the atmospheric phenomena by using backscatter profiles and time series images [7], to evaluate the cloud fraction [8], the aerosol layers height in the atmosphere as Saharan dust intrusions or volcanic ash $[9,10]$ and the PBL (Planetary Boundary Layer) dynamics studies [9].

We used data collected by two ceilometers located in southern part of Romania, one situated at Bucharest-Magurele (26.029E, 44.38N, 93m amsl) and the other at Strejnic $(44.55 \mathrm{~N}$ and $25.57 \mathrm{E}, 252 \mathrm{~m}$ asl). The ceilometer located at Magurele is installed 
on the roof of the Physics Faculty (20m above ground level) and managed by the University of Bucharest. The ceilometer installed at Strejnic is managed by National Institute of Aero-Spatial Research. Both instruments are VÄÏSÄLA CL31 type on single-lens technology, $910 \mathrm{~nm}$ wavelength, with $20 \mathrm{~m}$ vertical resolution and $2 \mathrm{~s}$ temporal resolution. Its laser diodes are pulsed with a repetition rate of $10 \mathrm{kHz}$ at high energy [11, 12]. Apart from ceilometer located at Strejnic which has the vertical range of determination up to only $4500 \mathrm{~m}$, the Magurele ceilometer is calibrated up to $7000 \mathrm{~m}$.

The geographical and climatological characteristics are different for the two locations. Magurele is situated nearby Bucharest, the largest town in Romania with strong urban and plain climatology. Strejnic is located at a higher altitude, nearly $200 \mathrm{~m}$ upper and has a climatology with mountain influences. Therefore, it is important to have both locations experiencing the same synoptic pattern at the same time. In order to increase the ceilometers' data accuracy we investigated the dates when the columnar air characteristics over the two locations were similar.

\subsection{Data and methods}

In order to find the days with Saharan dust intrusions, the ceilometers' measurements for months July, August and September 2016 were investigated simultaneous with daily dust intrusions forecasted by Dust Regional Atmospheric Model (DREAM).

Three days with coincident data were selected as study cases for analysis: July $17^{\text {th }}$ (case I), September $10^{\text {th }}$ (case II) and September $17^{\text {th }}$ (case III).

The ceilometers' measurements were processed using the Cloud View software. The output data consist of a text file for each day, every files includes cloud base-heights and aerosol layer heights with temporal resolution of 16s. These data were processed with LabView software to determine time series of the backscatter signals and the backscatter coefficient vertical profiles.

In order to have a good evaluation of the aerosols presence and characteristics, and because it is required another data source as satellite or lidar instrument to have a back-up for the investigation [11] we used in addition coincidental synoptic data, aviation meteorological and satellite data, confirming the originating dust storm.

To evaluate the atmospheric parameters and meteorological conditions we used multiple satellite products. The EUMETSAT analysis was extracted from the cloud product diagnosis Cloud Mask (CMa) from NWCSAF (Nowcasting and very Short Range Forecasting), which allows to identify the cloud types and cloud top temperature and height. In order to localize the source, we used the Single Scattering Albedo (SSA) at 550nm (it was found to be higher than 0.95 for dust [13]) provided by MODIS (Moderate Resolution Imaging Spectroradiometer) facilities, spectrometers abroad Terra and Aqua satellites. In order to find the dust source and monitor the plume dispersing path we used Absorbing Aerosol Index (AAI) from the Global Ozone Monitoring Experiment-2 (GOME-2). The Absorbing Aerosol Index (AAI) indicates the presence of elevated absorbing aerosols in the Earth's atmosphere. The aerosol types that are mostly seen in the AAI are desert dust and biomass burning aerosols.

The two ceilometers dataset were organized into an inter-comparison study in order to increase the data accuracy.

The air mass characteristics were evaluated performing vertical profiles from recomputed soundings with HYSPLIT computing facilities (GDAS, $0.5 \mathrm{deg}$ ) and Baneasa atmospheric sounding provided by the Romanian National Meteorological Administration.

\section{RESULTS}

Data from two ceilometers, were evaluated for three dust intrusion cases in order to determine ceilometer's capabilities to detect aerosol layers. The study was thought as an intercomparison between the data gathered from the two ceilometers with coincidental data and this is why the outcome consists in only three study cases. The analysis for the three cases started with the prognosis of DREAM and continues using all the announced data in Section 2.

For the first case the DREAM model is displaying a vertical profile of dust concentration around $45 \mu \mathrm{g} / \mathrm{m}^{3}$ value which is not exceeding the threshold value of $50 \mu \mathrm{g} / \mathrm{m}^{3}$. For the other two cases we found $48 \mu \mathrm{g} / \mathrm{m}^{3}$ to $50 \mu \mathrm{g} / \mathrm{m}^{3}$ at heights ranging from $1500 \mathrm{~m}$ to $3500 \mathrm{~m}$. The cross-section data from 
DREAM output is displaying values of 20$40 \mu \mathrm{g} / \mathrm{m}^{3}$ around $3000 \mathrm{~m}$ height (not shown) for the all three cases.

In order to locate the Saharan dust plume source we performed HYSPLIT trajectory model. The trajectories obtained are passing nearby the regions where dust/sand storms were certified as being active by the MODIS output data with Deep Blue Aerosol retrieval in two of the three cases with AOT values ranging from 1.17 to 1.52 .

Other sources, as synoptic and aeronautical data were used i.e.: confirmation on METAR telegrams for 15 September 2016 (case III) as blowing dust event for more than six hours at Biskra Airport (34.51N 05.44E).

EUMETSAT Dust Channel product with superimposed $500 \mathrm{hPa}$ contour field (ECMWF) (not shown) and WLK map product (not shown) are consistent with the dust trajectory displayed by the HYSPLIT trajectories model presented for the all dust events. The dust layers over the two stations were thin and sometimes dispersed. Therefore, because it was difficult to discern between aerosol layers and clouds, we payed attention especially to color and in the intensity of backscattering signals in units of $\mathrm{m}^{-1} \cdot \mathrm{sr}^{-1}$.

From the two time series obtained from the two ceilometers is clearly shown the presence of the low level clouds, which are confirmed by the analysis provided by the cloud product diagnosis Cloud Mask (CMa) from NWCSAF (Nowcasting and very Short Range Forecasting), EUMETSAT (not shown). This particular day (17.07.2016) was characterized by stratus clouds in the morning and broken clouds during daytime.

Study case I data are shown in Figure 1 where the red line is representing the backscatter vertical profile from Strejnic ceilometer. The profile is selected in a 30 minutes interval from 05:00 UTC to $05: 30$ UTC.

The vertical profile (Figure 1) gives us a more precise value for the maximum of the backscatter coefficient: $\beta=1 \cdot 10^{-4} \mathrm{~m}^{-1} \mathrm{sr}^{-1}$ at $2700 \mathrm{~m}$ height. Grater values of $4 \cdot 10^{-4} \mathrm{~m}^{-1} \mathrm{sr}^{-1}$ or the backscatter coefficient are displayed in lower levels, as 500$1100 \mathrm{~m}$, consistent with the EUMETSAT CMa product (not shown) which displayed Stratus/Fog presence at 06:00 UTC in the Strejnic region.

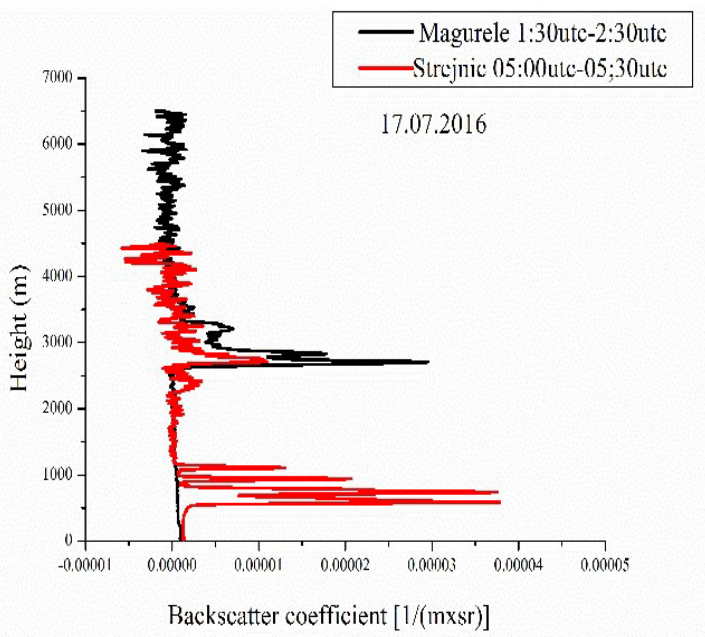

Figure 1. Superimposed backscatter vertical profiles from Magurele and Strejnic ceilometers

Magurele ceilometer backscatter coefficient vertical profile is represented in black line, showing consistency with Strejnic vertical profile i.e values of $1 \cdot 10^{-4} \mathrm{~m}^{-1} \mathrm{sr}^{-1}$ at $3000 \mathrm{~m}$ as the plume was dispersed. On the backscatter coefficient time series one can see a dispersed signal of the suspected dust intrusion between $2700 \mathrm{~m}$ and $3200 \mathrm{~m}$ (Figure not shown).

For the second and third study case there were obtained dispersed signals on time series backscatter coefficient image and values of beta below $0.5 \times 10^{-4} \mathrm{~m}^{-1} \mathrm{sr}^{-1}$ on backscatter coefficient vertical profiles situated at heights ranging 2000 to $3500 \mathrm{~m}$ (Figures not shown). Performing HYSPLIT model soundings facilities we have obtained similar columnar air characteristics for the two locations.

For the all three study cases we found the same similarities between levels of clouds or level of temperature inversion obtained from soundings and the correspondent levels obtained from CL31 measurements.

These similarities allow us to consider the measurements of the two ceilometers being consistent with the hypotheses that the Saharan dust intrusion was manifested on the two locations and ceilometers' measurements are correct and significant.

\section{CONCLUSIONS}

The CL31 ceilometer was found to be a useful instrument for determining the atmosphere 
proprieties. Although the Saharan dust plume discussed in this paper was a faint one, we have good reason to say that the ceilometer is capable to sense the aerosol even in little quantities.

Usage of two ceilometers with coincidental data would allow us to discern between the clouds and aerosol's layers within the same synoptic conditions but keeping in mind the existing geographical difference between the ceilometer's locations.

This study has shown the importance of having some other tools for backup when performing aerosol detection.

\section{ACKNOWLEDGEMENTS}

The authors gratefully acknowledge the NOAA Air Resources Laboratory (ARL) for the provision of the HYSPLIT transport and dispersion model (http://www.ready.noaa.gov) used in this publication. The authors gratefully acknowledge the permission to use the EUMETSAT satellite products with ECMWF data overlaid delivered by EUMeTrain e-PORT PRO, access permitted by courtesy of Mr. Andreas Wirth.

\section{References}

[1] Dittmann E, Barth S, Lang J, Muller-Westermeier G., 1995: Objektive Wetterlagenklassifikation (Objective weather type classification). Ber. Dt. Wettrd. 197, Offenbach a. M., Germany.

[2] Prospero, J. M., P. Ginoux, O. Torres, S. E. Nicholson, and T. E. Gill, 2002: Environmental characterization of global sources of atmospheric soil dust identified with the nimbus 7 Total Ozone Mapping Spectrometer (TOMS) absorbing aerosol product, Rev. Geophys., 40(1), 1002, doi: 10.1029/2000RG000095.

[3] Israelevich, P., Ganor, E., Alpert, P., Kishcha, P., and Stupp, A., 2012: Predominant transport paths of Saharan dust over the Mediterranean Sea to Europe, J. Geophys. Res.: Atmospheres, 117(D2).

[4] Vukmirovic, Z., Unkaševic, M., Lazic, L., Tošic, I., Rajšic, S., Tasic, M., 2004: Analysis of the Saharan dust regional transport, J. Meteorol. and Atmos. Phys., 85(4), 265-273.

[5] Forstner, J., B. Ritter, B. Vogel, D. Rigier, D. Majewski, H. Vogel, 2016: Assessment of the mineral dust related reduction of photovoltaic power generation in Central Europe with COSMO-ART and
ICON-ART Conf paper, Atmospheric DustDUST2016.

[6] Illingworth, A. J., RJ Hogan, E.J. O'Connor, D. Bouniol, J. Delanoë, J. Pelon, A. Protat, M.E. Brooks, N. Gaussiat, D.R .Wilson, D.P .Donovan, H.K .Baltink, G.J. van Zadelhoff, J.D. Eastment, JWF Goddard, CL Wrench, M Haeffelin, OA Krasnov, HWJ Russchenberg, J. M. Piriou, F. Vinit, A. Seifert, A.M. Tompkins, U. Willén, 2007: Cloudnetcontinuous evaluation of cloud profiles in seven operational models using ground-based observations, Bull. Amer. Meteorol. Soc., 88, 883-898, doi: 10.1175 BAMS-88-6-883.

[7] Ungureanu, I., S. Stefan, and D. Nicolae, 2010: Investigation of the cloud cover and Planetary Boundary Layer (PBL) characteristics using ceilometer CL 31. Rom. Rep. Phys., 62(2), 396-404.

[8] Stefan, S., I. Ungureanu, C. Grigoras, 2014: A survey of cloud cover over Magurele, Romania, using ceilometer and satellite data. Rom. Rep. Phys., 66(3), 812-822.

[9] Münkel, C., Eresmaa, N., Räsänen, J., Karppinen, A., 2007: Retrieval of mixing height and dust concentration with lidar ceilometer. Boundary-Layer Meteorol., 124(1), 117-128.

[10] Nemuc, A, I. S. Stachlewska, J. Vasilescu, A. Gorska, D. Nicolae, C. Talianu, 2014: Optical Properties of Long-Range Transported Volcanic Ash over Romania and Poland during Eyjafjallajokull Eruption in 2010, Acta Geophys., 61, 350-266. doi:102478/s11600-013-0180-7.

[11] Kotthaus S., E.O'Connor, C. Münkel, C. Charlton-Perez, M. Gabey, C.S.B. Grimmond, 2016: Recommendation for processing atmospheric attenuated backscatter profiles from VÄÏSÄLA CL31 Ceilometers. Atmos. Meas. Tech. Discuss, doi: 10.5194/amt-2016-87.

[12] VÄÏSÄLA Ceilometer CL31User's Guide.

[13]. Levy, R. C., Remer, L. A., Kleidman, R. G., Mattoo, S., Ichoku, C., Kahn, R., Eck, T. F., 2010: Global evaluation of the Collection 5 MODIS darktarget aerosol products over land. Atmos. Chem. Phys., 10(21), 10399. 